\title{
Communities and Scholarship in Supporting Early Career Academics at the University of Witwatersrand
}

\author{
Ruksana Osman* and David J Hornsby \\ University of the Witwatersrand
}

\begin{abstract}
The present paper reports on early career academics' (ECAs) experiences of support for teaching in a research-intensive university in Africa. Through conducting a questionnaire and follow up in-depth interviews greater insight into how ECAs perceive and experience support for developing their teaching practice, is gained. Our analysis suggests that most academics interviewed began their first teaching position with no preparation for all that teaching involves. Many struggled to balance the demands associated with teaching and research, in addition to familiarizing oneself with institutional teaching norms and cultures. Almost all found support from within their discipline, although such support was incidental and spontaneous rather than planned. We offer the idea of communities of practice $(\mathrm{CoP})$ as an approach to institutionalize support for ECAs and draw on the scholarship of teaching and learning (SoTL) as the theoretical framing for this study and experience from a South African institution.
\end{abstract}

Key words: ECAs, higher education, Africa, South Africa, communities of practice, scholarship of teaching and learning

\footnotetext{
*Corresponding author. Ruksana.osman@wits.ac.za
} 


\section{INTRODUCTION}

Although there has been a growth in the number of formal, mandatory and ad hoc interventions in higher education to support the teaching of academics, these interventions do not target ECAs explicitly and their teaching capabilities and skills (Solem and Foote, 2006; Foote, 2010). What is less clear is whether these initiatives work, what they afford and what they constrain (Warhurst, 2008). There is also the assumption that ECAs are a homogenous group maintaining similar needs and experiences (Gale, 2011). In this sense, supporting the next generation of academics requires more than simply investing in mandatory courses in teaching and teacher development. There is a need to reassess ideas and assumptions about professionalization of practice and professional development.

McAlpine and Akerlind (2010) comment how difficult it is to define who ECAs are and note the field of studying ECAs is under researched. Teaching and learning support for ECAs (those who completed their $\mathrm{PhD}$ in the last five years) is a relatively new area of study in South Africa. In the context of the 'aging professoriate' (Tettey, 2006) nurturing and supporting ECAs is fast becoming a priority in some universities. This support, particularly in relation to support for teaching and learning in higher education is also emerging in a context of educational change and wider transformation in higher education in South Africa and globally (Le Grange, 2005). Among other changes teaching and learning support for ECAs is posited as a key mechanism for responding to 'massification' of higher education and its concomitant effect of bringing in diverse students, improving access to higher education and improving success and pass rates in universities (Hornsby et al., 2013). It is also seen as a way to professionalizing teaching and learning in higher education (Brew, 2003) and responding to new modes of teaching and teaching delivery underpinned by varied education based technologies.

Higher education in South Africa, and globally, is under pressure to reinvent itself (Arum and Roksa, 2011). In South Africa, higher education has enjoyed the financial support of the government and has also enjoyed a relatively autonomous existence since the end of apartheid. However, policies have required that universities respond to a National Plan for Higher Education (DoE, 2001) that commits universities to become cost effective, streamlined institutions that compete for school-leavers who qualify for admission. Universities are required 
to generate strategies that broaden access routes for disadvantaged groups and at the same time consider curriculum strategies that ensure inclusivity and success to such groups after access. Massification in effect has translated into dealing with larger number of students, from more diverse backgrounds, and the transformation agenda in universities has meant that ECAs are far from homogenous. The sector has been seen as unwilling or even unprepared to deal with both of these issues. In addition to these daunting challenges, the higher education sector has experienced a decrease in government funding and an increase in government control (Le Grange, 2005). Policy also calls for institutions that are responsive to the academic and vocational needs of the economy and society.

While there is much research on teaching and learning in various disciplines (Foote, 2010; Prosser, Trigwell \& Taylor, 1994) and even research on how students learn (Marton and Booth, 1997; Prosser and Trigwell, 1999; Biggs, 2003), little is known about how ECAs experience support for teaching in research intensive universities in South Africa, with a few notable exceptions (Cilliers and Herman, 2010; Jawitz, 2009; van Schalkwyk, et al 2013; Quinn, 2012). Put another way, we know little about the demands ECA's face as teachers in large classes; about the structures and support they need or are in place that will enable them to succeed as teachers in higher education and about the policies that are driving these initiatives. Volbrecht and Boughey (2004) point out that in South Africa, there has been more emphasis on student development than on staff development.

Many institutions in South Africa already engage in support for teaching through centers for teaching and learning, or teaching and learning units or research centers of higher education (van Schalkwyk, et al 2013; Cilliers and Herman, 2010; Volbrecht and Boughey, 2004). But the focus on ECAs is relatively new and is emerging as an area of inquiry. As such institutions of higher education need to develop an expertise for teaching and understanding of learning amongst ECAs. Teaching activities in higher education have traditionally not been prioritized in the development of emerging academic talent. While teaching alongside research and academic citizenship is a priority in confirmation/tenure and promotion processes, ECAs teaching and learning needs are not always explicitly supported. Although the research on which this article is 
based was carried out in a South African research-intensive university, we argue that the perspective that it provides may apply for other universities in South Africa.

\section{THEORETICAL CONTEXT}

The scholarship of teaching and learning (SoTL) movement, in both ideational and structural ways, provides a useful way to think about how to support ECAs as they begin their scholarly teaching and reflective practice. It fits well within our context because it allows for framing discussions of teaching as part of the research that academics undertake. Such a framing makes possible that teaching becomes research driven and part of the expectations of scholarly activity within a disciplinary community. CoP then become fundamental in this circumstance as they act as the rally point for scholarship approaches.

The SoTL framework proposed by Boyer (1990) was a response to bridging the researchteaching divide that predominates higher education. The framework also articulates what it means to be a scholar (Campbell, 1991) and what scholarship in higher education can look like. Boyer (1990) identified four domains or types of scholarship: Discovery, Integration, Application, and Teaching. The major principles underpinning SoTL (the fourth domain) in higher education in general are that the academic investigates his or her own practices of teaching and/or the student's practices of learning; that the outcomes of such researched investigation are open for inspection and validation by colleagues and peers.

Shulman (2000) distinguishing between scholarly teaching and a scholarship of teaching, sees scholarly teaching as teaching that is underpinned by appropriate resources relevant to the discipline, and the scholarship of teaching is sharing our work with our peers and professional communities with an intention to build new knowledge about our field or discipline. It is precisely here that the research-teaching divide is disrupted and the transformative potential of scholarship of teaching for higher education is actualised for ECAs in a research intensive university. Boyer's (1990) notion that SoTL brings to the fore the interplay between learning, teaching and research, acts as a reminder that teaching is not distinct from research and learning. 
This suggests a move from scholarly teaching to scholarship in teaching which means developing an institutional context and climate that supports learning of the teachers; teachers who are able to innovate in their practice who have access to a community or a space in which teaching and learning can be reflected on and then opportunities for disseminating this work publicly.

Despite the many complexities that may be associated with supporting ECAs in a university such as ours, a scholarship of teaching and learning frame provides a useful approach to ways of thinking about how to support ECAs as they make their way in the university. Such an approach is helpful in understanding this developmental work, especially in societies where social and economic inequalities loom large and where the institutionalization of quality teaching and learning is still uneven across universities.

Ideationally as Le Grange (2005) has noted, focusing on SoTL can be a deconstructive force, bridging the competing responsibilities that university academics face such as service, research, and teaching. We suggest that taking a scholarly approach to teaching makes research in teaching and on teaching an attractive option for academics in higher education. Supporting ECAs in a way where research is in the service of teaching and as proposed by the SoTL framework, may go some way to creating CoP that enhance and satisfy the experience of ECAs, while at the same time advancing the social mission of university education. To this end the concept of $\mathrm{CoP}$ is employed as a device to intervene structurally and at the level of the institution to enable and institutionalise support for ECAs. Such an intervention makes possible that teaching becomes research driven and part of the expectations of scholarly activity within a disciplinary community. CoP then become fundamental in this circumstance as they act as the rally point for scholarship approaches. Brew (2003: 1) points out that if "the relationship between teaching and research is to be enhanced" then the idea of CoP are vital in universities.

CoP provides an elegant way for understanding the individual in context and how to institutionalise support for ECAs. Collin and Valleala (2005: 418) remind us that the individual and the social are at all times intertwined. Together they help us to think about cultivating a community of scholars and provide insight into features of such a community of scholars. 


\section{Situated learning theory and CoP}

Situated learning theory posits that learning is inherently social in nature. Lave and Wenger (1991) reject 'psychologistic' theories of learning in favour of a social and contextual approach. They contend that all learning is situated not only in time and space, but also in relation to social context. Adults learn from and with others, and engage with tools and activities in a social context known as a 'community of practice'.

CoP offer a good device on how to think about the institutional spaces for developing and supporting ECAs in strengthening their teaching capabilities. A CoP may be a formal collective of academics such as a special interest group. In many cases they are self-organised and selfselected groups of people who share a common sense of purpose and a desire to learn from one another. People learn as they become involved with a community or culture of learning, interacting with the community and learning to understand and participate in its history, assumptions, cultural values and rules (Hansman, 2001). For this to happen, learning requires time, and exposure to an increasing range of activities and artefacts in the CoP (Castle, Osman and Henstock, 2003). 
According to Wenger (1998: 93), the relationships within CoP are characterised by mutual engagement of the participants, binding them into a social entity, joint enterprise resulting from the collective process of negotiations, and a shared repertoire of communal resources, including "routines, words, tools, ways of doing things, stories, gestures, symbols, genres, actions, or concepts that the community has produced or adopted in the course of its existence". CoP allow us to think about professional development not only as a means to share or coordinate resources, but as a way to construct knowledge while working towards a shared goal, in our case teaching and learning in higher education. Competing discourses, rules and power relations may affect the learning within and across CoP more so because higher education as a sector does not represent a stable practice, and is in fact characterised by change and transformation, as discussed above.

\section{RESEARCH METHODOLOGY}

We set out to investigate ECAs' experiences of support for teaching in higher education and to understanding how in our university, they learn to teach. Further we sought to explore the development and support our university provides to early-career academics for their preparation and probing the suggestions that ECAs have about the support they need for teaching in higher education.

This study that is being reported on here was part of a larger study involving several universities on the African continent. The main aim of this project being to understand how ECAs in Africa are supported and can be supported in the domain of teaching in higher education. Such a study does pose some ethical considerations given that some ECA's are still going through the probation and confirmation process which means their employment status is not secured and the nature of asking about support does sometimes requires focusing on interpersonal relations. We sought to mitigate this process by going through the ethics review process and offering participants anonymity and confidentiality.

The present paper reflects a case study on ECA development as research was conducted at a single institution in South Africa, namely the University of the Witwatersrand (Wits). The predominant research method consisted of a 35-question questionnaire and in-depth interviews within a mix-method design. Such a design 
allowed us to draw on a large ECA community spread across a number of faculties and a plurality of lived experiences. The questionnaire permitted a macro understanding of ECA experiences at Wits followed by the interviews which enabled us to develop a richer and deeper sense of understanding ECA support. Methodologically we allowed for ECAs from different and sometimes competition disciplinary orientations to articulate their thinking around support for teaching in higher education. This in and of itself offers a means to open up space for expression to a group often little considered in higher education environments.

A sample size of 400 ECAs was generated through the assistance of Human Resources offices across the different Faculties. All Faculties with the exception of Commerce, Law, and Management agreed to provide contact information for individuals who had started lecturing at Wits in the last five years. We had 49 academics (12\%) respond to the questionnaire. Of this group 29 of the participants were female and 12 were male ( 8 individuals did not indicate their gender) and predominantly came from the Humanities (20 respondents) and Sciences (19 respondents). The remainder came from Engineering (5 respondents) and Health Sciences ( 2 respondents) faculties. Such a response rate is well within accepted norms for case studies (George and Bennett, 2005).

The racial breakdown of the questionnaire respondents was generated based on the categories established by the South African government and is as follows: 28 white, and 18 black ECAs. The questionnaire was developed by the project leader and adapted for relevance to the Wits environment. From the questionnaire, 17 ECAs (35\% participation rate) from across the four faculties and from a range of disciplinary backgrounds within the university, agreed to be interviewed. The questionnaire was a broad instrument that asked a range of questions relating to infrastructure, skills, perceptions of readiness, and experiences of support. From there the study focused on the theme of support and concentrated in-depth interviews around questions of the experience of the nature of support provided, the source of support, and what could be done better.

If as Jarvis (1992:17) believes, the learning of adults “....is located at the interface of people's biography and the socio-cultural milieu in which they live, for it is at this 
intersection that experience occurs..." investigating the experiences of ECAs is necessary, challenging and crucial. It presents an area of inquiry and scholarship that has rarely been explored in higher education in Africa. As such, the present paper and special issue fills a gap in the literature.

\section{INSTITUTIONAL SNAPSHOT}

Wits University is one of 25 universities' in South Africa that service a population of approximately 54 million people. South Africa is characterized by extreme economic and social inequality that is a legacy of the Apartheid system initiated to institute racial classification and segregation for much of the $20^{\text {th }}$ century. With the fall of Apartheid in 1994, the political and social project of the new democratic dispensation has focused on attempting to rectify the inequalities made common. In this sense, whilst South Africa is formally classified as a 'middle income nation' with advanced levels of infrastructure and governance systems and institutions, it remains 'developing' as a majority of the population continues to live in extreme poverty with only basic and often insufficient levels of education. In such a circumstance, higher education is central in efforts to 'fix' South Africa by being made the locus for the transformation of society. This has meant dramatic increase in enrollments to include people from previously disadvantage backgrounds. Indeed, the University presently sits at a student body of approximately 30,000 and an academic and support staff contingent of approximately 4,000. Wits also has a history as a research driven institution with significant institutional resources placed in fostering academic staff to publish. In South Africa, public funding for universities is tied to research output, which in part explains this motivation. But it should also be noted that Wits attempts to maintain an international profile for its research activity.

From around 2007 there has been a greater focus on teaching and learning more broadly, and recently an institutional emphasis on professionalizing teaching and learning practice. The Teaching and Learning Plan 2014-2019, explicitly commits to ensuring a quality teaching and learning environment, through offering greater support mechanisms for academic staff. In particular, the document recognizes the need for academic staff to have networks, scholarship opportunities, and development programmes that speak to good teaching practice (Wits, 2014: 9). The Centre for Teaching and Learning Development (CLTD) is meant to play a central role in 
implementing the teaching and learning plan and has recently reoriented its focus on supporting academics with a variety of courses and workshops that concentrate on supervision, evaluation, course design, lecture delivery and assessment. Their orientation is what Prosser and Trigwell (1999) call teacher focused, in other words a focus on how teachers can improve teaching. While an early career academic can access any or all of these courses, none of these courses are mandatory and nor do they target ECAs explicitly, i.e. those who are new to the university. In some Faculties attendance at a selection of courses on offer is essential for meeting probation requirements and in other Faculties the stance is more flexible.

\section{AN ANALYSIS OF ECAS' EXPERIENCES}

Insights from the questionnaire and interviews provided a rich reserve of information for understanding ECAs' experiences about teaching. Whilst the questionnaire was helpful in terms of signposting matters confronting early career academic support, the interviews provided depth in building understanding of who, how, where, and when ECAs received support. As such, from the interviews we were able to identify themes or issues pertaining to the experience of support for ECAs that are discussed below. We envisaged that this thematic approach would lead us to identifying crosscutting themes in relation to the broad research problem. Through focusing on cross cutting themes like induction; demands on ECAs; skill development; and support in light of such challenges in higher education as massification, it is possible to consider ways forward for assisting ECAs develop their teaching capacity in a research intensive institution. The four cross cutting themes provide a succinct way in which to summarise the data sources and provide the original contextual contribution to this article.

\section{Induction into teaching in higher education}

According to the questionnaire data, participants indicated that they did receive some level of guidance from their head of department or the course coordinator prior to teaching their first class. However, equal numbers also indicated that they received no advice before beginning teaching. See figure 1 .

Figure 1: Questionnaire Question 21 


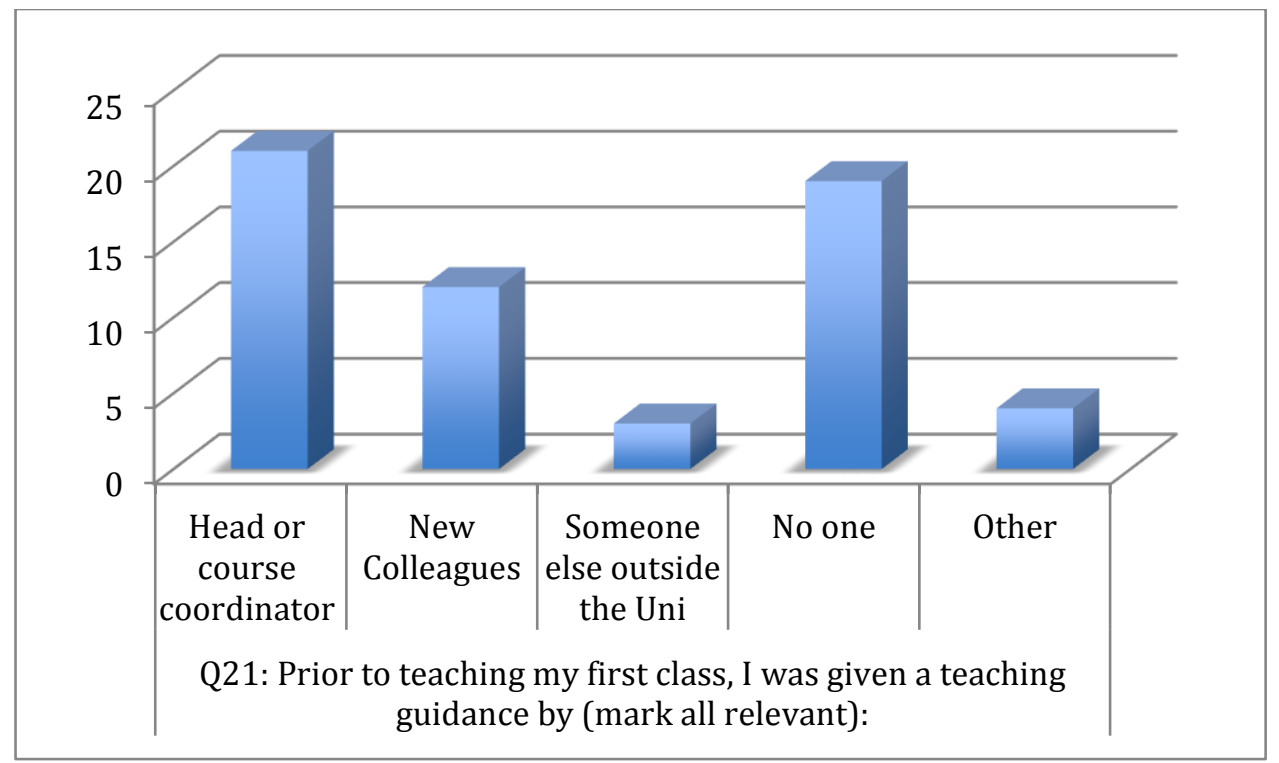

In exploring this questionnaire outcome in the interviews, it was confirmed that almost all the ECAs did not have any unsolicited formal training or advice on how to teach. There is a tacit assumption amongst those in leadership positions that if you have a PhD and have been a graduate student, you know your content and you speak well so you can teach. Feedback from the interviews was consistently typified by these two comments:

When I started there was no official induction and my head of school did not discuss teaching with me.

Support for teaching in the school only comes when the head of school gives approval for training requests. There is no institutional or faculty proactiveness.

In some cases, ECAs inherited all the lecture notes from a colleague and were expected to 'deliver' the content. There was no formal induction or support. In instances where there was some support, this was mostly ad hoc and spontaneous and always at the request of the early career academic. In pursuing this in the interviews the idea was reinforced, that unless an early career academic made a specific request for help and information, that no advice or feedback to teaching was given. As ECAs put it: 
I had to learn by trial and error.

...improving on the go with little feedback or checking in from colleagues

Fumbled around

...free reign to do as I pleased

Consistent with the experience of academics in the study conducted by Warhurst (2008), ECAs experienced having to learn to teach by trial and error without much formal and explicit support from heads of departments or senior staff members. We are reminded that experienced lecturers have to be available so that ECAs get the appropriate guidance to perform practices appropriate to the context. Learning (in this case to teach) requires time, and exposure to an increasing range of activities in the community of practice that is experienced as supportive and enabling and one in which teaching is valued. Wenger (1998) refers to reified artifacts as reflecting social histories. In a transforming context of higher education, ECAs come in with individual histories; higher education cannot make assumptions about a shared set of experiences of pedagogies; such a shared approach to the artefacts (like course notes) needs to be built and supported.

\section{Demands on ECAs in terms of teaching}

Balancing demands of research and teaching and administration was one that came up consistently. Balancing teaching and research was cited by all those who were interviewed as most demanding. The anxiety to balance the two becomes acute in an increasingly competitive environment and is seen as key to a successful academic career, as two academics pointed out:

It's really hard to balance teaching and research obligations, particularly when you are thrown into the deep end with teaching large classes upon arrival.

Balancing research and teaching is a challenge because you have to prepare course materials as well as start up your research program. 
This experience is consistent with findings in studies that ECAs feel vulnerable and insecure about their work in such environments (Hakala, 2009; Archer, 2008).

In addition to the complexity associated with balancing teaching and research, the line between teaching and administration was a fine one. As one academic put it:

I found it hard to distinguish between teaching and administration. Sometimes the admin was like teaching the course in terms of intensity. There were no hand over documents or induction enabling me to assess how far I needed to go with administration.

Blaxter et al., (1998) note that it is not just the number of roles that have to be balanced but also the weighting of these in the context in which ECAs find themselves in, such as research intensive or teaching intensive universities. Gale (2011) writing about ECAs in a teaching intensive university cautions that not all ECAs experience these fragmentary or competing roles in the same way. Using a transformational framework to explain ECAs' experiences Kligyte $(2011,202)$ notes that an important part of learning for ECAs is learning to manage the tensions between 'multiple duties' that are also experienced as 'incompatible.'. Simons et al., (1987) offers a teaching hierarchy of needs as a way in which various competing roles can be managed. We offer the SoTL framework as a way to smooth the tension between teaching and research.

Drawing on their experiences of teaching in other countries (as doctoral students), some ECAs pointed out that the diversity in the student body and the diversity in departmental norms added a layer of complexity to balancing teaching and research. Managing the multiplicity of demands came out in the interviews quite clearly:

I struggled with how to handle the diversity in student backgrounds and learning experience at Wits. This added complexity in a context where I was trying to figure out how to teach and was not something I experienced when I taught abroad. 
As such, it is important to keep in mind the various degrees of challenges that ECAs face when trying to determine how best to structure interventions in support of developing teaching practice. Like students, ECAs have multiple experiences and contexts from which they draw, meaning that any skill development initiative or CoP program needs to be sensitive to the diversity of experience and focus on shared norms and values.

\section{Skills development for teaching expertise}

Support for skill development came mainly from imitation of a former university teacher, a colleague, through or attending teaching courses as noted in Figure 2.

Figure 2: Questionnaire Question 22

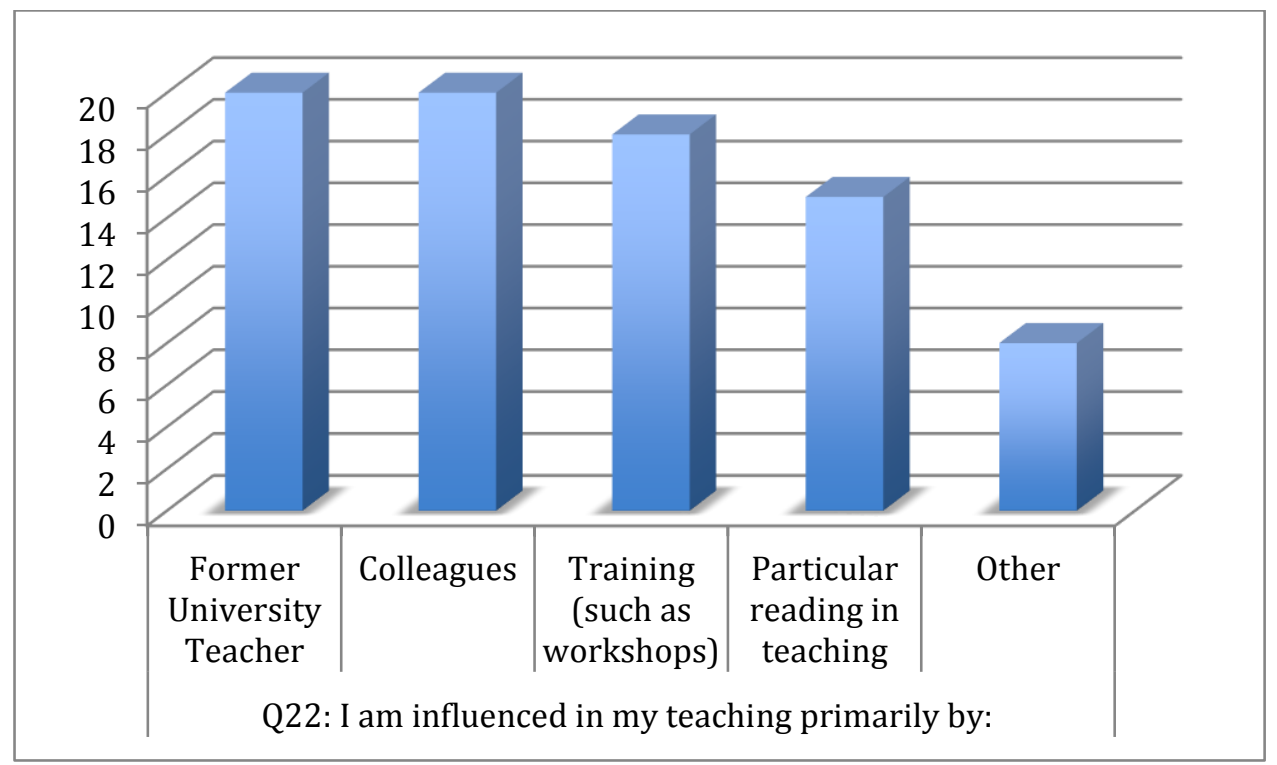

In the context of collegial support, the interviews confirmed that it was incidental and spontaneous. Indeed, it appears that purposeful pedagogic interaction was largely absent. In exploring this theme with interview participants, advice and suggestions from senior colleagues was only given if the new comer asked for it, as one participant put it:

knowing when to ask and what to ask required a lot of courage

Others said: 
There is not a lot of support [for teaching development] and certainly not enough of us to share knowledge. I really want to be embedded more in our discipline [teaching practices.] Instead, I feel quite lonely and isolated...

In contrast to advice and skill development for research, such for teaching was rare - if I wanted to talk about my research it was far easier than if I wanted to talk about my teaching.

Permitting such isolation of ECAs to continue can have deleterious effects on promoting effective teaching practices within a university. Colleagues within disciplines need to explore ways of engaging in discussions around teaching and learning as part of the regular school or departmental conversations. It appears that similar types of developmental conversations occur quite easily when it is about research but remain largely absent in respect to teaching. The teaching and research divide is quite sharp in this context. It is possible that scholarly teaching or teaching support was not part of senior colleagues developmental experience, as such is just not considered when an ECA joins a department. In this sense, many departments still see teaching as apart from research.

\section{Support for teaching large classes and the challenges of massification}

Consistent with findings by Warhurst (2008), ECAs in this study were not always given detailed documentation, records or 'hand over notes' for courses that they were going to teach. Some ECAs noted that they did receive PowerPoint notes with no conversation about the meanings associated with the content. As one colleague said:

When I started I was given the PowerPoint slides, tutorial questions, and exams for my course and was told to teach from them, and that was it.

Almost all of the academics felt like they were expected to adapt from day one with no induction or guidance on course assessment, evaluation, or administration for large groups. There is a growing body of work which points out that teaching large classes calls for a pedagogic stance that has an understanding of the issues about large class 
pedagogy (Hornsby and Osman, 2014). Such massification requires an understanding of teaching in diverse university classrooms. Instead, ECA overwhelmingly resorted to teaching approaches most common to particular disciplines (see Figure 3). Such approaches do not necessarily account for what is best for student learning or come informed with the best teaching or assessment techniques in large class formats. A focus on disciplinary specific teaching approaches also tends to focus on content rather than treating learning as a process where higher order cognitive skills like critical thinking or student engagement are privileged. In a context such as South Africa, where higher education is critical to the social and economic development goals of the country, developing students who are critical thinkers, able to navigate a complex social environment, and solve problems is crucial (Arvanitakis and Hornsby, 2016).

Figure 3: Questionnaire Question 23

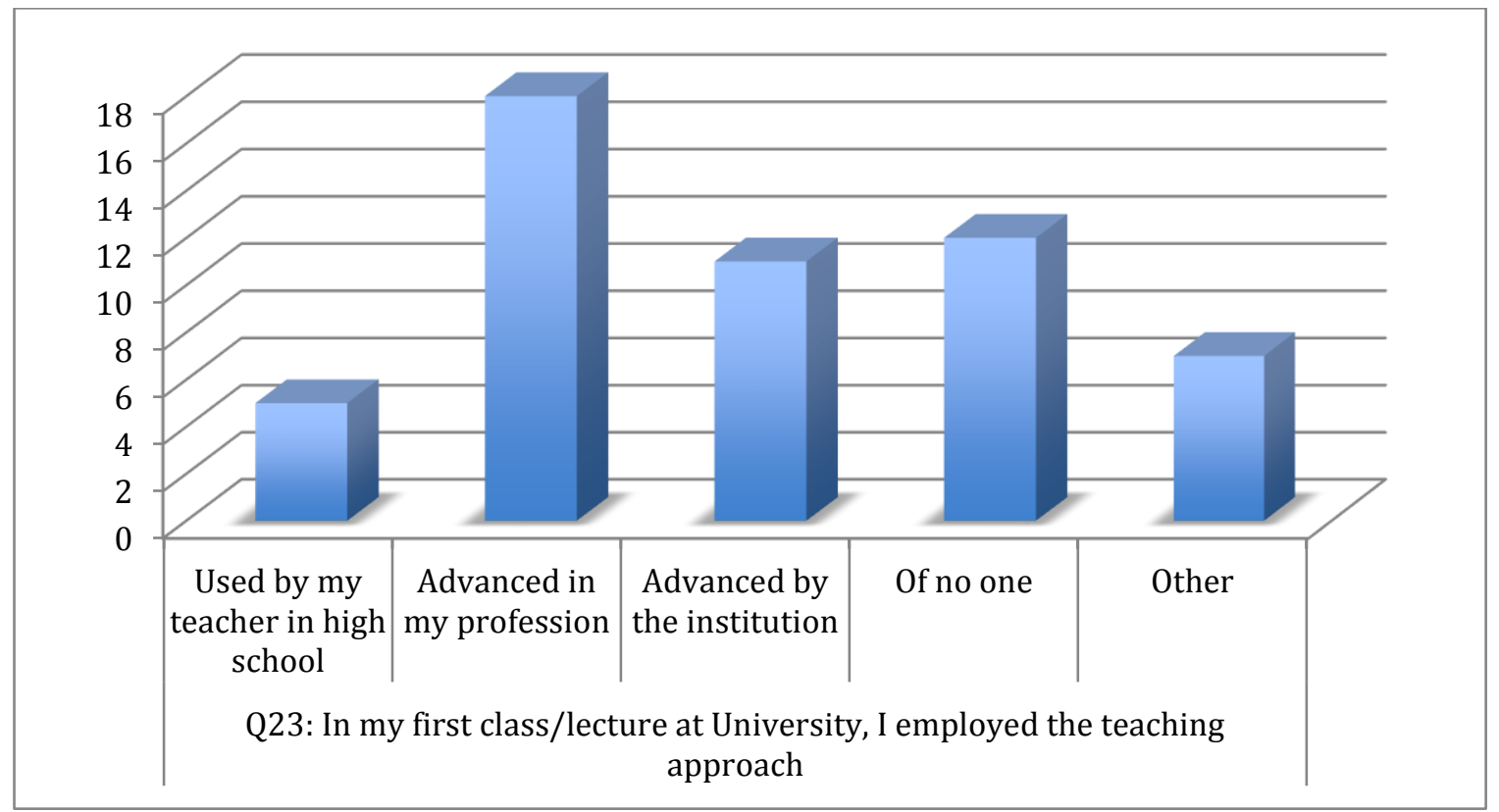

In analyzing the cross cutting themes emerging from the experiences of ECAs, it is clear that very little is taking place to systematically support them in a way that they think would be effective. This does not mean that institutions are not making efforts to support ECA. However, there is a fundamental disjuncture between what ECAs want and need, and what they are getting. This is a critical finding and speaks to the clear need for a rethink of how teaching support is positioned and provided at our university. 
Theoretically, what is of interest in Figure 3 is that the biographical line can be seen as the more influential in decisions about teaching approaches adopted. So the approaches that were adopted were those advanced by the profession. In Figure 2 it is those advanced by former university teacher and in Figure 1 it's "no one". Together these point to a distinct current lack of community of practice guidance on teaching approaches.

In a context where the sector of higher education is undergoing transformation in a variety of spheres and dimensions, these responses from ECAs is instructive. The data provides evidence for varied histories of pedagogic approaches in the South African context. At Wits it is clear from the data that there is an absence of guidance on teaching and learning, and certainly no shared understanding about what it entails or how it can be strengthened.

\section{IMPROVING EARLY CAREER ACADEMIC SUPPORT}

It is evident that support for developing expertise in teaching and learning is not to a level sufficient for ECAs at Wits. Interventions when they happen are either ad hoc or not constructed in a manner that ECAs feel are useful in their disciplinary contexts. Given this, it is necessary to consider how supporting ECAs could be better developed, and here, developing CoP might be helpful.

Wenger, McDermott and Snyder (2002: 51) identified seven conditions necessary in order to cultivate CoPs:

1. CoP's should be designed to permit natural evolution. This is because they are dynamic, with shifting interests, goals, and members

2. Open dialog should be at the core of CoPs as members and their knowledge need to have space to be expressed and for learning to occur

3. Accept and welcome that there will be different levels of participation by the three groups: the core group, active group and the peripheral group

4. Establish public and private community spaces where members share, discuss and explore ideas 
5. Allow opportunities for participants to explicitly discuss the value and productivity of their participation

6. Foster a CoP that is analytically eclectic - CoPs should offer the expected learning opportunities as part of their structure, and opportunities for members to shape their learning experience together...

7. Ensure that CoPs meet regularly. This will help develop members' capacity for reflection and evolution.

Given these conditions, the big question remains: at what level to establish and how best to structure such communities at Wits? Returning to the questionnaire and interview data offers some perspectives and guidance.

\section{Collegial CoP: A challenge of location}

Although all ECAs mentioned that they would go to the department for support or as the first port of call, the interviews highlighted that all felt the isolation of the newcomer. All new comers were given the largest classes to teach and usually the first year class and with no one checking on how teaching was coming on. Further, little in terms of what was taking place at an institutional level either resonated or was believed to be relevant to what the early career academic needed, as colleagues noted:

CLTD workshops are helpful but don't help with what is going on in your field.

Teaching support happening at the institutional level is not really pitched to help me grapple with problems I face with teaching in my discipline.

In this sense, colleagues interviewed noted that a CoP located at a more disciplinary relevant level is desired as it is believed that this level can provide more relevant insight into teaching discipline relevant content and addressing discipline specific problems. This fits well with Wenger's (1998) early work on CoP as linking meaning and identity - as identity here is strongly linked to a disciplinary knowledge base. Those in the Sciences mentioned how helpful the Teaching and Learning Centre in their faculty was once they figured out that it existed and that there were colleagues 
able and willing to provide help regarding teaching practice. But these colleagues were clear - such an entity assisted with teaching practice but not with grappling with some of the disciplinary relevant issues or with more established colleagues who insisted on particular teaching strategies:

My first experience of support was having the [Teaching and Learning Centre colleagues] come to my class. It is clear they are not content experts but they helped more with style.

Where institutional support for teaching development appears important, is in ensuring that broad based financial support exists for teaching and learning initiatives. As Figure 4 establishes, ECAs at Wits want teaching and learning training opportunities to be financially supported at the institutional level but the content of this training needs to be disciplinary relevant. As one participant noted:

I do not have much engagement with CLTD - it is isolated geographically but also topically in terms of my needs.

Figure 4: Questionnaire Question 31

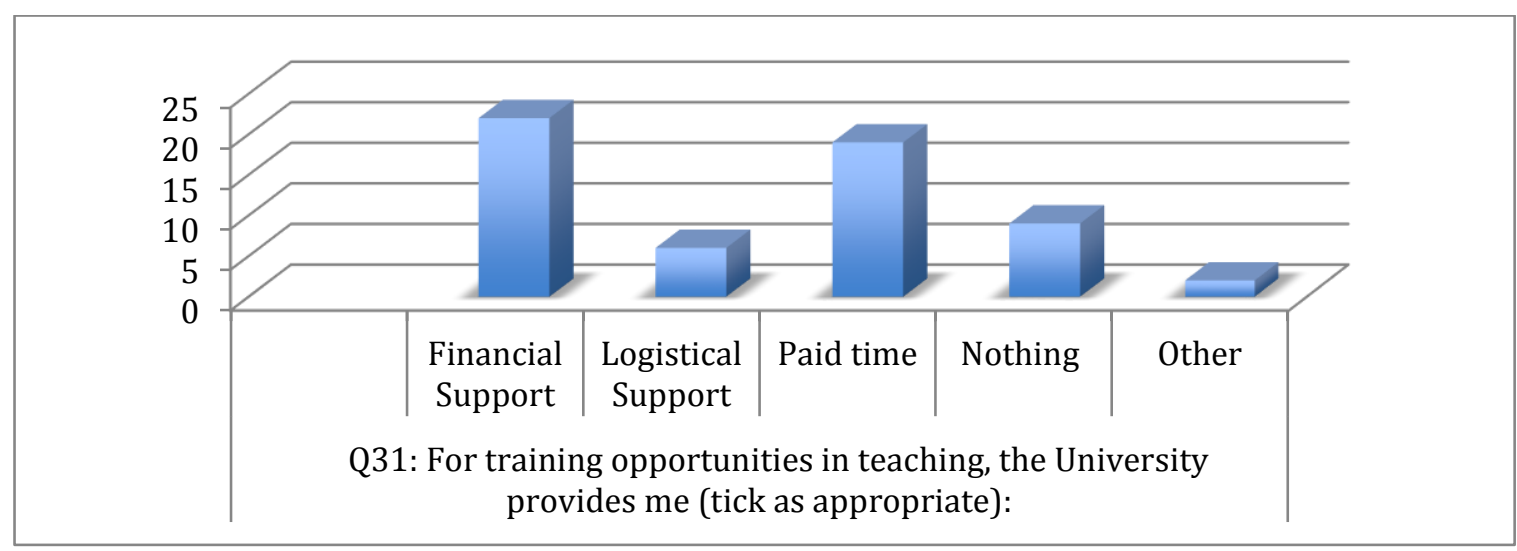

It appears that institutional financial support needs to go into activities that support logistical development in the sense of how to construct a syllabus, design assessments and even deliver lectures. That said, the interviews suggested that faculty and disciplinary relevant interventions are considered the most helpful in facilitating good teaching practice, engagement and understanding of curriculum development, 
assessment design and student learning. Overall, there is a sense among participants for a need to have an integrated model where content and pedagogy are taken together. In this sense, developing a localised community of support where disciplinary knowledge stays firmly in the picture.

So, it is clear that ECAs who participated in this research project believe that support for teaching practice development is crucial at an institution, but the level at which a $\mathrm{CoP}$ is fostered needs to maintain relevance to their disciplinary experiences.

\section{Communities as a way forward?}

So what sort of systemic interventions can occur institutionally that facilitates CoP emerging as desired by ECAs? In essence what is the mechanism that can motivate for a CoP that explicitly considers teaching and learning to emerge? Such a question really speaks to institutional priorities and directions. At Wits, transformation and research are important, thus we need to consider a mechanism that links these two priorities and incorporates support for teaching. And here, considering a framework offered by SoTL can be that mechanism in both constitutive and structural ways. SoTL provides a useful way to think about how to support ECAs as they begin their scholarly teaching and develop a virtuous cycle of improved teaching. It also fits well within an institution that places research as a strategic imperative, by framing discussions of teaching as part of the research that academics undertake. Indeed, a number of those interviewed noted that it was easy to discuss research objectives and goals with heads of departments rather than teaching. If one thinks about teaching and teaching support as scholarly teaching then a potential way forward emerges. Such a way makes possible that teaching becomes research driven and part of the expectations of scholarly activity within a disciplinary community. CoP become fundamental in this circumstance as they act as the rally point for scholarship approaches (Brew, 2003:1). Despite the many complexities that may be associated with supporting ECAs, a SoTL frame provides a useful approach to ways of thinking about how to support ECAs as they make their way in the university.

So, what opportunities present themselves for higher education when you have CoPs infused with SoTL? 
Thinking about an interrelationship between CoP and SoTL, and between ECAs that are being inducted into the university and forming their identities as researchers and teachers is best understood as a bridge between the individual, the disciplinary, and the institutional context which they find themselves in. This interrelationship enables ECAs to form and express themselves as academics who take a research driven approach to their teaching and helps smooth the tensions that emerge for them between research and teaching activities.

By linking SoTL to CoPs research led teaching is enhanced and it enables ECAs to test their practical knowledge and competences by sharing within dicsplinary and interdisciplinary pedagogical communities. In this kind of sharing, ECAs are developing new knowledge about their own professions, fields, and disciplines but also about themselves as emerging academics in a complex higher education terrain.

CoPs infused with SoTL also have transformative potential for universities as they present opportunities for cross disciplinary discussions and research. SoTL in this sense bridges disciplines as there are common themes that exist in our environments regardless of disciplinary orientation. Things like large classes, assessment and student approaches to learning, and effective pedagogical approaches. Arguably the bridge of SoTL goes some way in promoting a key attribute of the $21^{\text {st }}$ century university; interdisciplinarity.

CoPs that are infused with SoTL approaches promote research led culture to teaching where we move beyond a content driven, single focused and non-researched approaches to teaching in the classroom. SoTL operating within CoPs makes teaching and learning in university environments more transparent and open to scrutiny by students and peers. It could potentially build collegiality, through ensuring approaches are validiated by peer review and rigorous analysis which is usually disseminated publically (e.g. seminars, papers, colloquia).

Structural considerations can speak to overcoming the tensions between teaching and research and facilitate CoP through providing incentives to pursue SoTL. For example, grants for research into teaching and learning, and centres that focus on teaching practice at a more local level can be employed. The Faculty of Science at 
Wits has a well-established centre for teaching and learning that is considered by those interviewed as a good place for advice. Other faculties at Wits have followed suit with such a model but are in the early stages of setting up these support mechanisms. By encouraging ECAs to apply for funding that includes practice based research, disciplinary specific initiatives, publication support, and conference funding on teaching and learning issues, can help inculcate a culture of SoTL. Leadership is another structural condition that can make a difference to academic colleagues taking up SoTL and developing their own CoP. Having people who are in positions of leadership because of their interest and research in teaching and learning can help start the necessary conversations around teaching and learning within disciplinary contexts and be a source of help or inspiration for ECAs. As ECAs in this study have shown, leadership in this area needs to happen at a more local, disciplinary relevant level.

\section{CONCLUSION}

The findings from this initial foray into ECAs experiences of support for teaching in one research intensive university in South Africa supports the following conclusions:

- ECAs get no direct and explicit support for teaching.

- They draw the greatest support from disciplinary colleagues at departmental level but this support is spontaneous and ad hoc.

- Balancing research and teaching in an increasingly competitive environment is demanding, as research is experienced as prioritised over teaching.

The pressures on African and global higher education is not going to ease up in the near future, if anything it is going to intensify. Focusing on ECAs and exploring the support they need in order to professionalise and be responsive to a globalized context requires a relational understanding of context and content. This holistic approach is also called for by Remmik et al., (2011) which suggests that we cannot develop quick fix programs to support ECAs in their teaching; rather to focus on and engage with how they experience the support or lack thereof, and to create multiple ways in which ECAs can access support for teaching - wherever it is located in the world. From the experiences of ECAs at Wits it appears that it is important to emphasize research driven teaching through promoting a culture of scholarship around teaching and 
learning. Such a culture is best developed within disciplinary CoP that have a sense of a shared enterprise, and where the norms and values are common - especially in relation to pedagogic practices. This combination of scholarly disciplinary communities provides an enabling space in which ECAs can learn that art of teaching and learning in higher education.

\section{Annex A: Survey questions for Early-Career Academics Study}
1. Gender:
a. Female
b. Male

2. Race:

3. Nationality:

4. Birth Year:

5. Academic field (for instance, Biology):

6. Speciality (for instance, Marine Science):

7. Level of qualifications:
a. Honours
b. Masters
c. Doctorate
d. Other (specify)

8. Academic rank:
a. Lecturer
b. Senior lecturer
c. Associate professor
d. Professor
e. Other (specify)

9. Teaching department/unit:

10. Employment status/Conditions of employment:
a. Full time permanent
b. Full time fixed contract
c. Part time permanent
d. Part time contract
e. Other (specify) 
11. I joined the institution as a:
a. Tutor
b. Research assistant
c. Lecturer
d. Administrator
e. Other (specify)

12. I joined the institution as an academic (teaching) staff in year

13. My university time is divided into:
a. Teaching $\%$
b. Research $\%$
c. Community Service
d. Other (specify) $\%$

14. I joined the University driven by:
a. Prestige/fame
b. Salary
c. Benefits
d. Intellectual space
e. Other (specify)

15. The number of modules/courses I have taught since joining the institution (including the current semester while counting the same course taught every time) is:
a. $1-2$
b. $3-5$
c. $6-9$
d. $10+$
e. Other (specify)

16. In a scale of 1 (very poor) to 10 (excellent), I describe my passion to teaching as

17. I have had a teaching competence (experience/skills) prior to joining the University.
a. Yes
b. No
c. Other (specify)

18. If yes, in a scale of 1 (very poor) to 10 (excellent), I describe my teaching competence as

19. I have had training in teaching since joining the institution.
a. Yes
b. No 
c. Other (specify)

20. If yes, the extent of my training, in a scale of 1 (very poor) to 10 (excellent) could be described as

21. Prior to teaching my first class, I was given a teaching guidance by (mark all relevant):
a. Head or course coordinator at my unit/department
b. New colleagues
c. Someone else outside the university
d. No one
e. Other (specify)

22. I am influenced in my teaching primarily by:
a. Former university teacher
b. Colleagues
c. Training (such as workshops)
d. Particular reading in teaching at a university
e. Other (specify)

23. In my first class/lecture at University, I employed the teaching approach:
a. Used by my teacher in high school
b. Advanced in my profession
c. Advanced by the institution
d. Of no one
e. Other (specify)

24. I was particularly challenged in my earlier week(s) of first time teaching in:
a. Preparing syllabus/i
b. Teaching syllabus/i (such as time management, communication)
c. Managing students
d. Was not challenged at all
e. Other (specify)

25. I was particularly challenged in my last week(s) of first time teaching in:
a. Covering the scheduled syllabus/i
b. Developing assessment and evaluations
c. Managing volume of assignments
d. Was not challenged at all
e. Other (specify)

26. Since I started teaching, I received student complements on my teaching:
a. Frequently
b. Occasionally
c. Rarely 

d. Never
e. Other (specify)

27. Since I started teaching, I received student complaints on my teaching:
a. Frequently
b. Occasionally
c. Rarely
d. Never
e. Other (specify)

28. In a scale of 1 (very poor) to 10 (excellent), I rate my academic preparedness to teach in the University as

29. In a scale of 1 (very poor) to 10 (excellent), I rate my methodological preparedness to teach in the University as

30. In a scale of 1 (very poor) to 10 (excellent), I rate my overall preparedness to teach in the University as

31. For training opportunities in teaching, the University provides me (tick as appropriate):
a. Financial support (cover expenses for training, for instance)
b. Logistical/material support (replacement in my absence)
c. Paid time (Salary)
d. Nothing
e. Other (specify)

32. To improve my teaching (even) more, I would prefer:
a. Financial support (cover expenses for training, for instance)
b. Logistical/material support (replacement in my absence)
c. Paid time (Salary)
d. Nothing
e. Other (specify)

33. To better prepare early career academics, I advise:
a. Mandatory institutional policy on teaching in universities
b. Emphasizing the importance of teaching through financial incentives/rewards
c. Raising the importance of teaching through academic promotion/recognition
d. Nothing
e. Other (specify)

34. As a teacher, I am considered a good role-model by students:
a. Yes
b. No 

c. I am not sure
d. Other (specify)

35. Please share with us relevant issues of Early Career Academics in this space:

PS: We greatly value your opinion and would appreciate a brief discussion to gather further insights from you. If you are able so spare 20 minutes, kindly provide contact details below:

Email address:

Phone number.

Thank you very much once again for your time and effort. We value them greatly!

\section{Annex B: Sample of Interview Questions}

1. When you first arrived, what sort of support was made available to you to enhance your teaching practice?

2. How do you think teaching is valued at Wits, in your faculty, and in your discipline?

3. How do you balance research and teaching obligations?

4. Are you encouraged to conduct research on your teaching practice?

5. What do you think is needed to improve support for quality teaching at Wits? 


\section{BIBILOGRAPHY}

Archer, L. (2008). Younger Academics' Constructions of 'Authenticity', 'Success' and Professional Identity. Studies in Higher Education, 33(4), 385-403.

Arum, R., \& Roksa, J. (2011). Academically Adrift: Limited Learning on College Campuses. Chicago: University of Chicago Press.

Arvanitakis, J and Hornsby, DJ. (eds). (2016). Universities, the Citizen Scholar, and

the Future of Higher Education. Critical University Studies Series. Palgrave

MacMillan Publishers.

Boyer, E (1990). Scholarship Reconsidered: Priorities of the Professoriate. San Francisco: Jossey-Bass.

Brew A. (2003). Teaching and Research: New Relationships and Their Implications for Inquiry-based Teaching and Learning in Higher Education. Higher Education Research \& Development, 22 (1) 3-18.

Campbell, G. R. (1991). "Scholarship Reconsidered", in the Journal of Extension, 29(4) Found at: http://www.joe.org/joe/1991/winter/tt1.html.

Castle, J., Osman, R., and Henstock, V. (2003) "Coupling'school experience'with community service: a case study." Education as Change 7(1), 3.

Cilliers, F. J., \& Herman, N. (2010). Impact of an Educational Development Programme on Teaching Practice of Academics at a Research-intensive University. International journal for academic Development, 15 (3), 253-267.

Collin, K., \& Valleala, U. M. (2005). Interaction among Employees: How Does Learning Take Place in The Social Communities of the Workplace and how might Such Learning be supervised? Journal of Education and Work, 18 (4), 401-420.

DOE, Republic of South Africa. (2001). National Plan for Higher Education. Department of Education.

Foote, K. E. (2010). Creating a Community of Support for Graduate Students and Early Career Academics. Journal of Geography in Higher Education, 34 (1), 7-19.

Gale, H (2011) The Reluctant Academic: Early-Career Academics in a Teaching Orientated University, International Journal for Academic Development, 16 (3), 215227. 
George, A. L., \& Bennett, A. (2005). Case studies and theory development in the social sciences. Cambridge, Mass: MIT Press.

Hakala, J. (2009). The Future of the Academic calling? Junior Researchers in the Entrepreneurial University. Higher Education, 57 (2) 173-190.

Hansman, C.A. (2001) Context-based adult learning. In S. Merriam (ed) The New Update on Adult Learning Theory. New Directions for Adult and Continuing Education, 89, San Francisco: Jossey Bass, 43-52.

Hornsby DJ, and Osman, R (2014) 'Massification in Higher Education: Large Classes and Student Learning,' Higher Education, 67(6): 711-719.

Hornsby DJ, Osman R, and De Matos Ala J. (eds). (2013) Teaching Large Classes: Interdisciplinary Perspectives for Quality Tertiary Education. Higher Education Series, SUN Press.

Jarvis, P. (1992). Paradoxes of Learning: On becoming an individual in society. San Francisco: Jossey Bass.

Jawitz, J (2009). Learning in the Academic Workplace: The Harmonization of the Individual and the Collective Habitus. Studies in Higher Education, 34 (6), 601-614.

Kligyte, G. (2011). Transformation narratives in academic practice. International Journal for Academic Development, 16(3), 201-213.

Lave J and Wenger E (1991). Situated Learning: Legitimate Peripheral Participation. Cambridge: Cambridge University Press.

Le Grange, L. L. (2005). The Scholarship of Teaching as Deconstructive Force. Education as Change, 9 (1), 185-196.

Marton F, Booth S. A (1997). Learning and Awareness. New Jersey: Lawrence Erlbaum Associates.

McAlpine, L., \& Åkerlind, G. (Eds.). (2010). Becoming an academic: International perspectives. Basingstoke, UK: Palgrave Macmillan.

Prosser, M., \& Trigwell, K. (1999). Understanding Learning and Teaching: The Experience in Higher Education. Buckingham: Society for Research in Higher Education and the Open University Press.

Prosser, M., Trigwell, K., \& Taylor, P. (1994). A phenomenographic study of academics' conceptions of science learning and teaching. Learning and instruction, 4(3), 217-231. 
Quinn, L. (2012) (Ed). Re imagining Academic Staff Development: Spaces for Disruption. Stellenbosch: Sun Media.

Remmik, M., Karm, M., Haamer, A., \& Lepp, L. (2011). Early-career academics' learning in academic communities. International Journal for Academic Development, 16(3), 187-199.

Simons J.A., Irwin, D.B., and Drinnien, B.A. (1987). The Search for Understanding West Publishing Company, New York.

Solem, M. N., \& Foote, K. E. (2006). Concerns, Attitudes, and Abilities of EarlyCareer Geography Faculty. Journal of Geography in Higher Education, 30 (2), 199234.

Shulman L. S. (2000). Teacher Development: Roles of Domain Expertise and Pedagogical Knowledge. Journal of Applied Development Psychology. 2 (1). 129135.

Tettey, W. J. (2006). Challenges of Developing and Retaining the Next Generation of Academics. New York: Partnership for Higher Education in Africa.

van Schalkwyk, S., Cilliers, F., Adendorff, H., Cattell, K., \& Herman, N. (2013). Journeys of Growth towards the Professional Learning of Academics: Understanding the Role of Educational Development. International Journal for Academic Development, 18 (2), 139-151.

Volbrecht, T. \& Boughey, C. (2004). Curriculum Responsiveness from the Margins? A Reappraisal of Academic Development in South Africa, in Griesel, H. (Ed.), Curriculum Responsiveness: Case Studies in Higher Education, Pretoria: SAUVCA.

Warhurst, R. P. (2008). 'Cigars on the Flight-deck': New Lecturers' Participatory Learning within Workplace Communities of Practice. Studies in Higher Education, 33(4), 453-467.

Wenger E (1998) Communities of Practise: Learning, Meaning and Identity. Cambridge: University of Cambridge Press.

Wenger, E., McDermott, R., \& Snyder, W. M. (2002). Cultivating communities of practice: A guide to managing knowledge. Boston, MA: Harvard Business School Press. 
Wits. (2014). Teaching and Learning Plan. Accessed on August 14, 2015 at http://www.wits.ac.za/library/aboutus/managementinformation/419/strategic_plan.ht $\underline{\mathrm{ml}}$ 